\title{
Fotografia Panorâmica e sua Relação Homem-Técnica
}

\section{Panoramic Photography and its man-technology relationship}

\begin{abstract}
Resumo:
Buscamos neste artigo discutir, a partir dos aportes de Gilbert Simondon e outros autores afins, alguns aspectos das relações entre objetos técnicos e a sociedade atual. Entendendo que humanidade e técnica estão inseridas nas mesmas etapas de evolução que se desenvolvem por um longo processo de individuações, assinalamos como eixo de nossa análise a discussão sociotécnica das condições do surgimento da fotografia panorâmica, bem como dos modos de subjetivação que permeiam esse processo. Assim, buscamos construir uma breve filosofia da técnica relativa à fotografia panorâmica, sem exaltar a ideia da relação homem e máquina como dominação, ou como uma mistura indistinta, mas sim disparando reflexões em que homem e máquina acoplados são produtores de modos de viver, que estão em constantes movimentos de instabilidade e estabilidade nas suas diferenças e semelhanças acionando processos de individuação e subjetivação.

Palavras-chave: Fotografia panorâmica. Objeto técnico. Processo de individuação. Relação homem-técnica.
\end{abstract}

\section{Abstract:}

We seek to discuss in this paper some aspects of relations between technical objects and current society, points taken from Gilbert Simondon and others related authors. In the understanding that humankind and technology are inserted in the same evolutionary steps that have been developed by a long individualization process, we mark as the axis of our analysis the socio-technical discussion about the conditions of panoramic photography arising, and the subjectivation modes that are intrinsic in this process as well. So, we seek to build a brief piece of philosophy of the technology that relates to the panoramic photography, without exalting the idea of the man and machine relations as domination, or as a indistinct blend, but just starting the reflections where man and machine coupled are producers of the live modes that are in constant movement of instability and stability in their differences and similarities triggering individual and subjectivation processes.

Keywords: Panoramic Photography. Technical object. Individuation process. Man-technology relationship.

MENDONÇ, André Noronha Furtado de; THOMAZONI, Andresa Ribeiro; BISCHOF, Tânia Gomes; FONSECA, Tania Mara Galli. Fotografia Panorâmica e sua Relação Homem-Técnica. Informática na Educação: teoria \& prática, Porto Alegre, v. 13, n. 2, p. 102-111, jul./dez. 2010.

\author{
André Noronha Furtado de Mendonça \\ Andresa Ribeiro Thomazoni \\ Tânia Gomes Bischof \\ Tania Mara Galli Fonseca \\ Universidade Federal do Rio Grande do Sul
}

\section{Introdução}

D ensamos a relação homem-máquina a partir da produção maquínica de subjetividade e entendemos, assim, que sujeito e tecnologia não correspondem a pólos distintos e dicotômicos, muito menos a antigas oposições entre natural e artificial. Falamos de um engendramento entre homem e máquina, cuja produção de territórios existenciais se dá em rede e fluxos, pelos mais diversos pontos. Então, nos referimos a um mundo no qual a subjetividade é engendrada, produzida em meio a um campo de forças sociais, do qual não se exclui o arsenal tecnológico.

Entendemos a subjetividade em constante produção, assim não se trata da ideia de um sujeito fechado, que tem uma origem ou é imutável. Subjetividade está imersa num campo de produção, constituído por saberes e coisas, de forma que alguns elementos são capazes de constituir-se em vetores de subjetivação.

Simondon (2008) pensa a gênese dos sujeitos e dos objetos técnicos a partir de um princípio de processualidade e de evolução 
do ser. Este processo evoca uma evolução não-contínua, que se efetua por saltos, num tempo não-linear. Evolução acaba, então, por confundir-se com o processo de individuação, no qual indivíduo e meio são correlativos de uma mesma gênese. Há, portanto, uma simultaneidade na gênese do sujeito e do objeto.

Deleuze e Guattari (2007) estendem a ideia de máquina para uma noção mais ampla, que inclui máquinas técnicas, sociais, econômicas e estéticas. Nessa perspectiva, há, então, agenciamentos maquínicos de subjetivação que se instauram como relações entre sujeitomundo, possibilitando múltiplos efeitos entre o agenciamento homem-máquina.

Assim afirmamos, com Parente,

[...] se a máquina resulta de um complexo processo de subjetivação, e se a subjetividade é fruto de um agenciamento social múltiplo, não há por que separar a máquina e o homem sob a base da oposição natural/artificial. Todo corpo tem suas artificialidades, toda máquina tem suas virtualidades: são os agenciamentos sociais nos corpos e nas máquinas. (PARENTE, 2010, p. 94)

O pensamento de Simondon (2003) não se refere a um indivíduo-sujeito-fechado em sua totalidade, acabado e estável. Na perspectiva do processo de individuação, ressalta-se a defasagem do ser em indivíduo e meio. Assim, o meio é o correlato do indivíduo, criado ao mesmo tempo que ele. A técnica seria, então, um desdobramento do ser, possibilitando que o sistema sujeito-mundo seja reinventado toda vez que se cria um objeto.

Para Escóssia,

[...] a vida é definida como um processo de evolução que se caracteriza por uma zona intensa de diferenciação. Esta diferenciação que no homem se dá no nivel fisiológico, prossegue fora dele, através da técnica. Sendo assim a técnica é um processo de diferenciação, na medida em que prolonga a vida por outros meios que não a vida. (ESCOSSIA, 1999, p. 44)

Entendemos a técnica "[...] como uma dinâmica que retroage sobre os homens, sobre a inteligência, os sentimentos e sobre os valores culturais [...]" (ESCÓSSIA, 2003, p. 178). A partir disso, o homem é capaz de vir a operar os objetos técnicos para além de suas possibilidades, numa espécie de torção inventiva, cujas forças combativas sejam capazes de produzir outros mundos possíveis. Buscamos, portanto, conforme Lévy (1990), reafirmar que a possibilidade técnica refere-se a uma micropolítica em atos. A técnica como ato, como fase de uma atividade de relação entre o homem e seu meio, possibilita que o objeto técnico progrida no meio, retorne sobre o homem e lhe permita se modificar e evoluir. Os processos de criação coletivos, produzidos hoje em redes de informática, são decorrentes desta torção inventiva produzindo saberes coletivos e simultâneos em âmbito mundial. $\mathrm{O}$ tempo não é mais linha cumulativa, pulsão, o espaço é tempo.

Simondon (2003) foi um dos pensadores que articulou a relação homem-técnica e incluiu esta última como fundamental para compreensão da relação homem-mundo. As técnicas são cada vez mais singularizantes e oportunizam a metaestabilidade ${ }^{1}$, ou seja, as informações ressoam internamente no sistema de forma fracionada não sendo algo objetivo e eterno. É ressonante, requer relações entre as diversas dimensões do que se é. É nesta troca de informações que a vida acontece (ESCÓsSIA, 2003). A metaestabilidade opera no âmbito de troca de informações homem-técnica como um ato técnico-ético-estético em que o passado ressoa no presente como virtualidade, fazendo problema no presente e potencializando o devir deste ato.

Destaca-se, ainda, que este processo homem-técnica é estruturado em rede, pois como um ato-ético-estético ele se desdobra entre outros atos transversais, laterais, produzindo modos de subjetivação que nos processos de interação articulam relações e saberes em constantes movimentos, devires. Assim, buscaremos discutir a tecnologia da fotografia panorâmica a partir de sua metaestabilidade, bem como, da sua apropriação pelo homem na produção de modos de subjetivação.

\footnotetext{
1 Simondon argumenta que é impossível compreender metaestabilidade sem introduzir "[...] a noção do potencial energético residente em um determinado sistema, a noção de ordem e de um aumento da entropia." (GLOSSÁRIO..., 2011 , p. 302). Este termo designa uma situação que está longe do equilíbrio. Situações metaestáveis têm magnitudes mais elevadas de energia do que aqueles simplesmente estáveis. Assim Simondon escreve: "A individuação, portanto, deve ser pensado como uma solução parcial e relativa manifesta em um sistema que contém potencialidades latentes e abriga uma certa incompatibilidade com ela própria, uma incompatibilidade devido a forças em tensão, tanto quanto a impossibilidade de interação entre os termos devido a suas dimensões díspares [...]" (GLOSSÁRIO..., 2011, p. 300).
} 


\section{Fotografia Panorâmica e sua Evolução Técnica}

Ganguilhem (apud ESCÓSSIA, 1999) traz o quanto a história humana é pensada em continuidade com a matéria e a vida, na qual a técnica seria a forma através da qual o homem continua a vida e a expande. Assim, o mais importante não reside em explicar a máquina, mas sim em compreendê-la.

Buscamos, então, traçar uma perspectiva da evolução técnica da foto panorâmica, de forma a fazer parte do processo evolutivo da própria vida e da própria humanização. Dessa maneira, consideramos a relação entre cultura e natureza, cultura e técnica, natural e artificial como dimensões de um mesmo processo de organização ou evolução da vida.

Desde sua alvorada, o homem faz do uso da construção de imagens um instrumento de experimentação de novos mundos, reais e imaginários. A geração de imagens panorâmicas foi desenvolvida com a finalidade de produzir no observador uma sensação de imersão vivencial de novas realidades. Segundo os historiadores do design gráfico, Meggs e Purvis (2009), a produção de imagens panorâmicas foi trazida pela primeira vez, ao universo gráfico humano, por Bernardo de Breidenbach, na obra Peregrinationes in Montem Syon, impressa em 1486.

Breidenbach pretendia realizar expedições pelo litoral norte africano e retornar à Europa vendendo suas façanhas em livros de contos e aventuras. Para isso, Breidenbach teve que contar com a florescente tecnologia gráfica de sua época e com as habilidades artísticas do ilustrador Erhard Reuwich, que, em 1483 foi então contratado para embarcar e registrar as paisagens de suas viagens. As gravuras panorâmicas de Reuwich foram impressas em páginas dobráveis de até mais de quatro páginas de comprimento, permitindo ao leitor experimentar a sensação presencial em lugares exóticos e nunca antes imaginados pelo cidadão europeu em finais do século XV.

O sucesso deste tipo de experiência permitiu o avanço no uso de recursos imersivos com a mesma finalidade, a partir do emprego de imagens panorâmicas. Em fins do século XVIII, mais precisamente em 1787, o escocês Robert Barker adaptou o uso de imagens panorâmicas já difundido pela indústria gráfica e imaginou o que aconteceria se ao invés de pá- ginas em livros, tais imagens fossem pintadas em painéis de grande formato, gerando não páginas, mas ambientes imersivos. Com isso, Barker inventa o Panorama, causando grande impacto em sua época.

Podemos pensar aqui, o quanto o experimento de Breidenbach, encontrava-se de certa forma latente, na invenção de Barker. Pois a ideia inicial de reproduzir ambientes imersivos possibilitou o pensamento saltar para além daquele outro que a engendrou, surgindo assim a invenção de Barker. O invento de Barker provoca uma intensa corrida tecnológica para produzir novos sistemas e novos dispositivos de imersão ambiental, com propósitos múltiplos, entre eles: propaganda política, turismo e diversão. Parente (1999) irá definir esses sistemas como espetáculos imagéticos.

Como abordado por Simondon (2008), a tecnologia humana apresenta uma gênese em processo de aperfeiçoamento, uma evolução cujos avanços nem sempre serão lineares, ocorrendo por vezes, em paralelo. É o caso, justamente, da evolução da fotografia analógica e da fotografia digital.

De forma similar ao universo biológico, a evolução tecnológica também apresentará nichos e disputas em que nem sempre sobrevive o mais forte, mas o mais apto. Simondon (2008) diz que a evolução poderia em efeito, ser considerada como uma adaptação, ou seja, a busca de um equilíbrio estável por redução da distância entre o vivo e o meio. Mas em sua perspectiva, a palavra adaptação junto com a ideia de impulso vital devem ser substituídas pela "[...] noção de individuação de sistemas sobresaturados, concebido como resoluções sucessivas de tensões por meio de descobrimentos de estruturas no seio de um sistema rico em potencial [...]" (SIMONDON, 2008, p. 172).

Estes potenciais de um sistema acabam por constitui-se em seu poder de devir, sem degradar-se, assim não são uma simples virtualidade dos estados futuros, senão uma realidade que os empurra a ser.

Apropriando-se de conceitos apresentados por Simondon (2008), uma máquina fotográfica em nossos dias não é a evolução direta de um equipamento desenvolvido décadas atrás, mas o resultado da convergência de saberes técnicos muitas vezes desconexos em seus propósitos originais. A evolução técnica não é linear. 
Assim, podemos pensar o quanto de realidade humana reside na máquina fotográfica, que operações foram precisas para que o gesto humano pudesse ser fixado e cristalizado em estruturas que funcionam. O que foi preciso ser sustentado no transcurso de seu funcionamento, que aberturas foram precisas para que se pudesse ter uma maior liberdade de funcionamento? Enfim, essas são algumas perguntas que fazemos ao objeto técnico que a máquina fotográfica constitui, a partir de sua perspectiva ontogenética, ou seja, "[...] ao devir do ser enquanto ser que se desdobra e se defasa individuando-se [...]" (SIMONDON, 2003, p. 102).

As etapas sucessivas de estruturação individuante, vão do estado metaestável ao estado metaestável por meio de invenções sucessivas de estruturas. Assim, a tecnicidade que se manifesta por meio do emprego de objetos pode ser concebida como algo que aparece em uma estruturação que resolve provisoriamente os problemas plantados pela fase primitiva e original da relação do homem com o mundo (SIMONDON, 2008).

Como na natureza, os objetos técnicos não surgem prontos, eles emergem do intelecto humano, como manufaturas, como conceitos, como possibilidades inventivas. Posteriormente, o conceito, o protótipo, é posto à prova e, submetido ao mercado, é aceito ou não, adapta-se ou não, sobrevive ou não. Tal condição será descrita por Simondon como a passagem do estado abstrato ao estado concreto:

O artesanato corresponde ao primitivo dos objetos tecnológicos, isto é, ao estado abstrato. A indústria corresponde ao estado concreto dos objetos tecnológicos (SIMONDON, 2008. p. 46).

Na gênese do objeto tecnológico câmera fotográfica, podemos pontuar o surgimento de seu conceito com a câmera escura. O primeiro texto descrevendo seu funcionamento é atribuído a Aristóteles. Leonardo Da Vinci também descreve seu princípio operacional no Codex Atlanticus:

Quando as imagens dos objetos iluminados penetram num compartimento escuro através de um pequeno orifício e se recebem sobre um papel branco situado a uma certa distância desse orifício, vêem-se no papel, os objetos invertidos com as suas formas e cores próprias. (UNIVERSAL Leonardo, 2011)
Os pintores renascentistas e barrocos fizeram uso da câmera escura para retratar com fidelidade fotográfica as paisagens retratadas neste período, observando o princípio descrito por Da Vinci. A ideia de se projetar a luz no papel formando imagens, inclusive, coloridas, instigou a possibilidade de se sensibilizar superfícies, registrando, em definitivo, as imagens nelas projetadas. Tal necessidade resultou na invenção da fotografia. A fotografia química, na forma como a conhecemos, parece ter origens diversas, sendo sua invenção atribuída ao francês Joseph Niepce, em 1826. Poucos anos depois, a técnica de Niepce foi aperfeiçoada por Daguerre. Porém, existem evidências de que esta invenção tenha sido de fato consolidada no Brasil, por Hércules Florence, em fins da década de 1820.

Foi a possibilidade do conhecimento em se materializar nos meios técnicos que possibilitou o surgimento da câmera fotográfica para o registro da fotografia. Diversos elementos, numa rede em agenciamento singular permitiram o registro fotográfico e sua fixação, tais como a lente, filme, iluminação, propriedades químicas do suporte, etc. Podemos nos referir a esse movimento, a partir da tecnicidade que a câmera fotográfica possui, ou seja, a tecnicidade não se encontra no grau de automatismo, mas sim na margem de indeterminação que a máquina é capaz de preservar. É esta margem que permite à máquina ser sensível a informações do exterior. Assim, até hoje há uma modulação²desse aparato técnico desenvolvido a partir de diversas pesquisas científicas, e produzido em escala industrial pelo mercado.

A tecnicidade nunca deve ser considerada como uma realidade isolada, senão como parte de um sistema. É a realidade parcial e a realidade transitória, resultado e princípio de uma gênese. Resultado de uma evolução, é depositária de um poder evolutivo, precisamente porque possui como solução de um primeiro problema o poder de ser uma mediação entre o homem e o mundo (SIMONDON, 2008, p. 174).

Neste processo evolutivo, a primeira câmera fotográfica considerada um equipamento gerador de imagens panorâmicas foi a de

2 Modulação entendida como a possibilidade de moldar de maneira contínua e perpetuamente variável (SIMONDON apud DELEUZE; GUATTARI, 2007, p. 91). 
Von Martens em 1844 e possuía um sistema giratório de varredura para sensibilizar a imagem no filme. O dispositivo de Von Martens era interessante, pois desenvolvia uma impressão de varredura em uma superfície cilíndrica, o que simula, com razoável aproximação, o comportamento da visão humana, que é tronco-esférica. A imagem revelada em papel fotográfico poderia ser impressa ampliada ou projetada em painéis semi-circulares com o propósito de gerar ambientes panorâmicos com experiência de imersão.

A câmera de Von Martens consistia num sistema giratório de varredura (scanning câmeras) nas quais as lentes eram rotacionadas sobre um eixo a partir do movimento de uma manivela que acionava um fuso sem fim. Conforme o movimento da manivela, o corpo de lentes percorria por todo o cenário e sensibilizava faixas diferentes de uma mesma chapa de filme, completando-se o registro da imagem panorâmica ao fim do curso do giro da manivela. Embora este equipamento proporcionasse a criação de imagens de grande amplitude angular, a técnica ainda não permitia a geração de imagens em 360。. A Figura 1 ilustra como funcionava este equipamento.
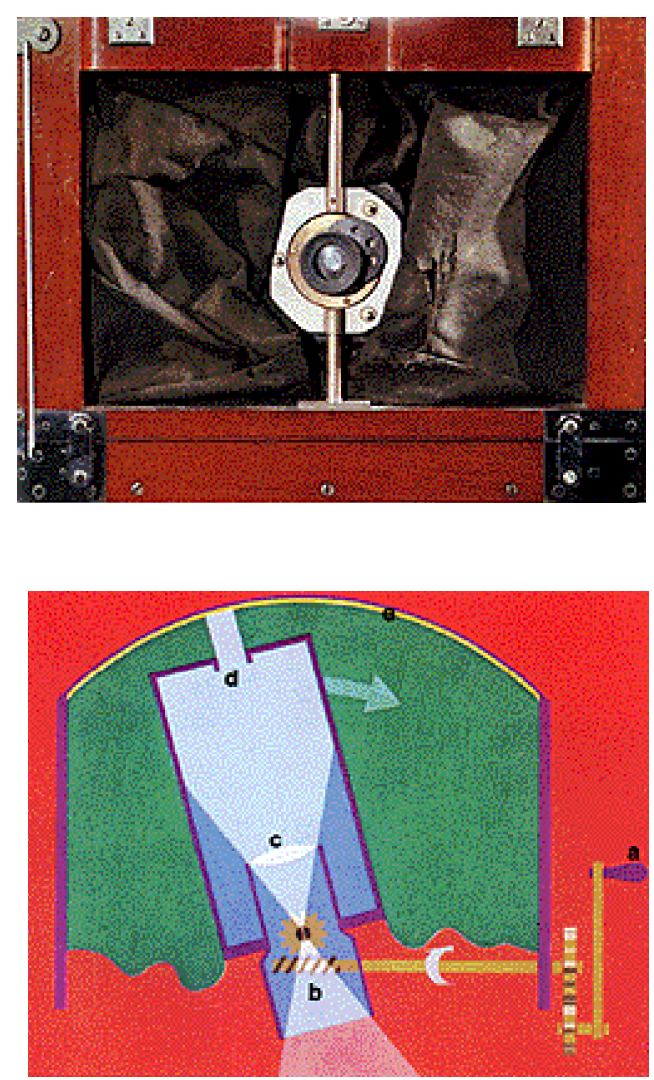

Figura 1 - Máquina Fotográfica de Von Martens. FONTE: Bigshotz, (2009)
Em 1900, os irmãos Lumiére apresentaram o Photorama, um dos primeiros modelos para a geração de imagens fotográficas em 360 graus, o que representou um enorme ganho de resultado em relação ao invento de Von Martens, pois permitia o registro de uma paisagem fotográfica instantânea, completa e em todas as direções no plano cilíndrico.

A apresentação do Photorama foi realizada para a feira internacional de Paris. O equipamento desenvolvido por Auguste e Luis Lumiére consistia de um dispositivo com 16 câmeras fotográficas que eram disparadas simultaneamente, e cujas imagens sensibilizavam uma única chapa disposta no centro de um cilindro. O filme depois de revelado era exposto em gigantescos painéis panorâmicos de 360。. A Figura 2 apresenta o Photorama e a tela de projeção como montada na feira de 1900 .

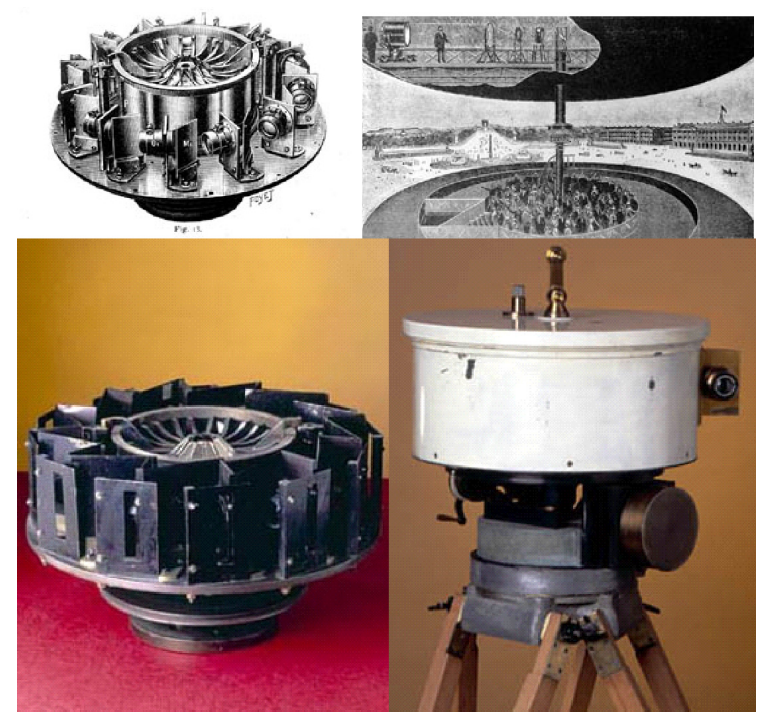

Figura 2 - Photorama dos Irmãos Lumiére. FONTE: Institut-Lumiere, (2009)

Ao longo do século $X X$, foram desenvolvidas importantes inovações na geração de imagens panorâmicas e em 360 graus. Um dos equipamentos mais relevantes foi a câmera Cirkut, produzida entre os anos de 1904 e 1944 e que ainda hoje encontra adeptos e usuários.

O projeto consistia em um sistema rotor para a câmera cujo giro acontecia em sincronia com o carretel do filme. Conforme ocorria o giro da câmera no eixo do rotor, o filme era gradativamente exposto e sensibilizado, formando uma imagem em 360. A Figura 4 apresenta uma tela panorâmica produzida em 1925 com este tipo de equipamento. 


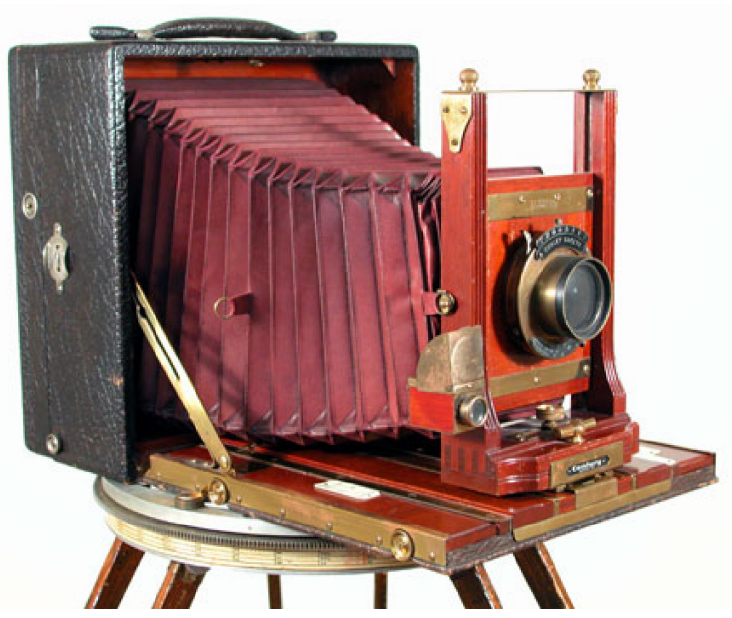

Figura 3 - Câmera Cirkut Eastman Kodak, 1907. FONTE: Historic Camera (2009)

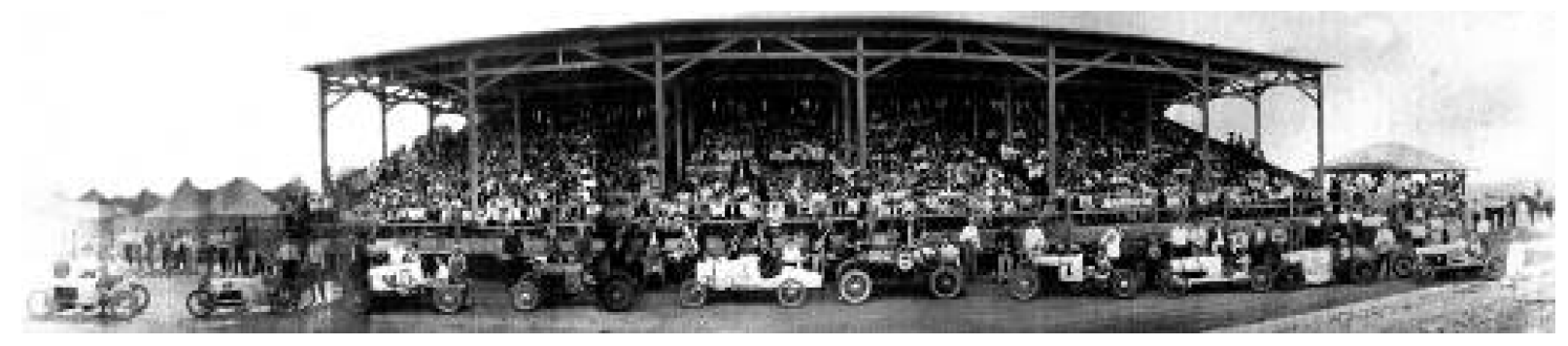

Figura 4 - Foto Panorâmica a Partir de uma Câmera Cirkut, Oklahoma, 1925. FONTE: Winfield (2009)

A partir dos anos de 1990 temos o início de uma transição entre os equipamentos analógicos e os digitais. Embora a passagem da tecnologia analógica para a tecnologia digital ocorra ao longo da década de 1990, sua evolução remonta à passagem entre os séculos XIX e XX. Esta evolução ocorre a partir de estudos do fenômeno fotoelétrico, observado pela primeira vez por Hertz em 1887, mas definido e descrito por Albert Einstein em 1905. Ou seja, de certo modo, a evolução da fotografia digital ocorre em paralelo à evolução da fotografia analógica.

O avanço de serviços de inteligência e espionagem a partir dos anos de 1950 durante a corrida armamentista no pós-guerra, em pleno ambiente hostil de polarização mundial entre o capitalismo norte-americano e o comunismo soviético, também conhecido como guerra-fria, deu início à corrida espacial e ao esforço pelo domínio de tecnologias que proporcionassem a observação silenciosa de manobras inimigas. Isto originou o desenvolvimento de satélites artificiais como sondas de exploração remota. As perspectivas pa- reciam irrestritas: observar o movimento de tropas, a expansão de cidades, de fábricas, o transporte de cargas e identificar que países possuíam riquezas minerais desta ou daquela natureza, indicando qual destes deveria ser invadido e conquistado. Aviões de reconhecimento exigiam elevadas altitudes para operação segura de riscos e o deslocamento de recursos humanos em territórios não aliados. O uso dos satélites proporcionava a oportunidade de estar no local exato, na hora exata, sem custo energético e sem o deslocamento humano. Por outro lado, com o avião, é possível resgatar um rolo de filme negativo. Com um satélite isto não é possível. As imagens precisavam ser transmitidas por uma alternativa não física. O que proporcionou isso foi o uso de tecnologias desenvolvidas a partir da física do efeito fotoelétrico. As imagens precisavam ser digitalizadas, processadas e enviadas para a Terra em sinais de alta freqüência. Tais avanços permitiram a transmissão quase simultânea, em diversos canais de TV em todo o mundo, dos primeiros passos do homem na Lua em 1969 e, pouco tempo depois, as pri- 
meiras imagens de Júpiter, e de Saturno e dos confins de nosso sistema solar emitidas pelas sondas Voyager 1 e 2, lançadas em 1977. Assim, o desenvolvimento de equipamentos digitais é um processo que permanece ocorrendo até os dias de hoje.

Para Simondon (2008), toda essa rede, cujos elementos e atores são ativados, os satélites, o capitalismo, a guerra, a transmissão, o efeito fotoelétrico, enfim, todos eles, manifestam em si, quando entram em ação, mais exatamente, suas facetas estéticas. Para ele, "[...] uma ferramenta, uma máquina ou um conjunto técnico são belos quando se inserem em um mundo humano e o cobrem a expressá-lo [...]" (SIMONDON, 2008, p. 204). Assim, a realidade técnica, a modulação fotoelétrica que é capaz de chegar vinda de outro lugar, de outro continente, traduzida em imagens, atravessando ruídos e distorções, é tecnicamente bela porque chega carregada da superação dos obstáculos, como uma singela testemunha de algum aspecto da vida, de uma cidade, de uma região.

Na geração de imagens panorâmicas e em 360 graus, um exemplo importante é o modelo Roudshot D3 QTVR, lançado em 2009 e que consiste em um sistema de 645 lentes do tipo olho de peixe, de $24 \mathrm{~mm}$, distribuídas esfericamente e alimentando de imagens um mesmo equipamento.

Assim se formam as imagens em 360 de imersão esférica.

De certa forma, o princípio da composição deste tipo de equipamento guarda relação conceitual com o projeto desenvolvido pelos irmãos Lumiére em 1900. Outras empresas que desenvolveram sistemas semelhantes foram a SpherocamHDR e a Panoscan. Por outro lado, a transição de modelos analógicos para digitais exigiu não apenas avanços tecnológicos nos equipamentos, como também avanços na tecnologia do processamento digital de imagens.

Em fins da década de 1980 os irmãos Knoll iniciam o desenvolvimento da linguagem PostScript que permitiu avanços nos mais diversos setores da indústria da imagem. Com relação ao campo que compreende a manipulação digital de imagens, destaca-se um importante software no mercado de aplicativos com licença proprietária: o Photoshop. Outro software importante nesta cronologia foi $O$ QTVR (Quicktime VR), desenvolvido pela Apple em fins dos anos de 1990.
O QTVR é importante porque permitiu a visualização de filmes interativos panorâmicos e em 360 graus em computadores pessoais. O desenvolvimento de softwares para o processamento de imagens digitais compreendeu tanto a tecnologia de processamento de imagens em computadores pessoais como a tecnologia de captura de imagens em câmeras fotográficas ou de vídeo.

Os equipamentos atuais para registro de imagens apresentam o sistema TDI (Time Delay Integration), que permite a captura de imagens com atividade local, ou seja, com o movimento de elementos no ambiente. A tecnologia TDI elimina o tempo de espera no sistema de varredura de imagem e tem sido aplicada em equipamentos de radiografia, microscopia e em escâneres de última geração, que já não varrem linha por linha a imagem como em sistemas convencionais. Este recurso permite fotografar a imagem simplesmente, num intervalo de tempo compatível com modelos analógicos. Antes da tecnologia TDI, mesmo imagens panorâmicas ou em 360 , gravadas no instante da filmagem apresentavam zonas fora de foco ou com efeito fantasma em elementos que estivessem em movimento. Hoje, os equipamentos que possuem este tipo de tecnologia permitem fazer uma imagem digital estática panorâmica ou em 360 graus de forma instantânea. Fotos panorâmicas obtidas a partir da montagem por manipulação em programas como o Hugin (livre) ou o Photoshop (proprietário) ainda não apresentam esta mesma eficiência.

\section{Fotografia Panorâmica e Metaestabilidade}

A imagem panorâmica retrata a cena composta de imagens que ampliam o campo de visão, ou seja, o que se captura pela máquina neste tipo de foto não é da ordem da captura do olho humano. Este acoplamento da tecnologia nos processos cognitivos acionam processos de subjetivação produzindo o dividual ${ }^{3}$ no corpo-cognitivo

\footnotetext{
3 Dividual: união de duas forças que produzem algo que combinadas com outras forças ou sozinhas são outro processo. Cada força é uma que juntas produzem algo. Exemplo $\mathrm{H} 2 \mathrm{O}$, água. O $\mathrm{H}$ ou o $\mathrm{O}$ separados são algo, combiandos com outras forças acionam outras composições. Nota dos autores.
} 
O desmembramento da tecnologia da foto panorâmica possibilita apreender o movimento em uma velocidade e captura da luz pela máquina. Neste processo, há presença de movimento e de captura de imagens nas quais sujeitos interagem, produzindo algo da ordem da subjetividade. É um encontro não da ordem do monismo e nem do espírito e matéria, mas sim da ordem do dividual, ou seja, duas forças potentes que juntas produzem algo e que podem se reconfigurar com outras forças e compor outros dividuais.

Este constante acoplamento se deve a relações do homem ao longo do século passado referendando as tecnologias como produzidas e produtoras de modos de subjetivação. A modernidade foi fortemente caracterizada pela produção em série e a lógica capitalista na qual qualquer movimento de desterritorialização, do instituído, de imediato acabava sendo capturado e reterretorializado. A partir da Segunda Guerra a lógica da produção em massa se transforma com o desenvolvimento de tecnologias digitais, da produção em série para a produção individualizada, mas ao mesmo tempo totalizante. Da sociedade capitalística para uma vida capitalística (PELBART, 2009).

Assim propomos o uso da tecnologia da foto panorâmica como uma tecnologia que quando apropriada por um sistema individuado faz problema, potencializa o que está na ordem do virtual produzindo outros modos de subjetivação. Destaca-se que este processo homemtécnica é único e não único, é estruturado em rede, pois como um ato-ético-estético ele se desdobra entre outros atos transversais, laterais, produzindo modos de subjetivação que nos processos de interação articulam relações e saberes em constante movimento.

Sob esta dimensão, Simondon (2003) possibilita introduzir a concepção de individuação, ou seja, há um corpo individuado, mas é sua abertura que articula um devir e o produz como um sistema aberto que vai mover-se no interjogo de forças produtoras de modos de viver. Evidentemente podem existir forças que não produzem o que se chama de bom encontro, pois levam a uma entropia, ou seja, ao enfraquecimento daquilo que constitui o ser.

Simondon (2003) concebe o equilíbrio como interação de forças que levam a uma organização. Equilíbrio é movimento constante de forças que se alinham para, no momento seguinte, se desestruturar na busca de um ou- tro equilíbrio. O equilíbrio é movimento, devir, aberturas e não fechamentos. Assim, retomase o conceito de metaestabilidade quando a

[...] fronteira entre o estável e o instável, não só é mantida pelo indivíduo como também carregada com ele, de maneira que o indivíduo constituído transporta consigo certa carga associada de realidade pré-individual (reservatório de possíveis). Essa natureza pré-individual, que permanece associada ao indivíduo, é uma fonte de estados metaestáveis futuros de onde poderão sair novas individuações. Na realidade o indivíduo só pode ser contemporâneo de sua individuação, contemporâneo do princípio. O indivíduo não é somente resultado, mas meio de individuação. (ACCIOLY, 2006, p. 1)

A foto panorâmica é um dispositivo sociotécnico decorrente de tramas afetivas, curiosas, transgressoras, dominadoras, interessadas, maquínicas, capitalísticas, ousadas, que, em diferentes tempos, retratam modos de subjetivar, modos que retratam o vivido e que compõem neste complexo de passado/ presente, o futuro. A foto panorâmica é um agenciamento articulando forças e potências de indivíduos, máquina e tecnologia. Ela é produtora de metaestabilidade.

\section{Considerações Finais}

Pensarmos a evolução da fotografia panorâmica, exige de nós uma perspectiva ampla, de um mundo que está em constante composição, numa rede híbrida, com diversos atores e múltiplos elementos heterogêneos. Assim, a fabricação da câmera fotográfica, até a possibilidade de materializar a fotografia panorâmica, envolveu e continua a envolver diversos agenciamentos. Refletem-se, nesta evolução criadora, movimentos de operação que se tornaram necessários na rede sociotécnica, na propagação, na difusão, etc. em direção à possibilidade de produção de diferença, e, por conseguinte, de produção de subjetividade .

A criação da câmera fotográfica é indissociável de diversas linhas de variação, variação da câmera escura, variação da possibilidade de se pintar paisagens em painéis, variação da possibilidade de se registrar em suporte químico a marca da luminosidade, variação do conjunto de diversas lentes prontas a sensibilizar uma chapa cilíndrica, variação da 
produção de imagens a partir da fotografia analógica e digital, variação de softwares de imagens. É variação da interrelação de afetos e técnicas, individuação e processo criativo, que retratam, produzem e são produzidos por movimentos atravessados por desejos, invenção e conhecimento. Da mesma forma, colocase a invenção do humano em suas diferentes individuações, sempre inacabadas e parciais. Nada pode ser considerado como concluído, tudo deve ser inserido em um longo e incessante processo de produção.

A tecnicidade de Simondon, pode ser aproximada da ideia de phylum maquínico, desenvolvida por Deleuze e Guattari (2007). Phylum maquínico ou linhagem tecnológica acontece cada vez que "[...] deparamos com um conjunto de singularidades, prolongáveis por operações, que convergem e a fazem convergir para um ou vários traços de expressão assinaláveis [...]" (DELEUZE; GUATTARI, 2007, p. 87).

A linhagem tecnológica é capaz de mudar e entrar em variação a partir do seu phylum maquínico ou de seus agenciamentos. Assim, os dois são inseparáveis. E a invenção tornase possível nessa perspectiva, por um agenciamento ${ }^{4}$. Trata-se, então, de seguir na matéria-fluxo que o mundo constitui, seu phylum maquínico, a variação capaz de carregar em si singularidades e traços de expressão.
Um ponto importante em toda essa concepção do modo de existência dos objetos técnicos, do qual Simondon (2008) soube falar tão bem, consiste na beleza que alguns objetos técnicos são capazes de portar. Beleza esta que aparece quando os objetos estão inseridos no mundo, seja geográfico ou humano. Assim, a impressão estética torna-se relativa a essa inserção, como um gesto. "A vela de um navio não é bela quando não funciona, senão quando o vento a infla e inclina inteiramente os mastros, levando o navio sobre o mar [...]" (SIMONDON, 2008, p. 203). A fotografia panorâmica torna-se bela quando suas imagens nos levam à imersão em uma paisagem, instante cuja fascinação efêmera lança o olhar a outras possibilidades de encanto imagético. Jogo de luz e paisagem, capaz de fazer o mundo eclodir aos nossos sentidos, retratar os desejos e anseios de quem a produz. A foto panorâmica é afecção no encontro do autor que a concebe e afeç̧ão junto àquele que nela é imerso produzindo agenciamentos afetivos. Como refere Simondon (2008, p. 205), "[...] o objeto estético não é um objeto propriamente dito, senão mais uma prologação do mundo natural ou do mundo humano que permanence inserida na realidade que o suporta; é um ponto destacável de um universo".

\section{Referências}

ACCIOLY, M.I. Simulação na Era da Convergência Digital. Razon y Palabra, México, n. 53, out./nov., 2006. Disponível em: <http://www.razonypalabra.org.mx/anteriores/n53/maccioly.html. Acesso em: 01 ago. 2011.

ADOBE Systems. 2011. Disponível em: <http://www.adobe.com> Acesso em: 01 maio 2011.

APPLE Quicktime. 2011. Disponível em: <http://www.apple.com/quicktime> Acesso em: 01 maio 2011.

DELEUZE, G.; GUATTARI, F. Mil Plâtos: capitalismo e esquizofrenia. São Paulo: Ed. 34, 2007. V. 5.

ESCÓSSIA, L. Relação Homem-Técnica e Processo de Individuação. Aracaju: Ed. UFS, 1999.

ESCÓSSIA, L. Por uma Estética da Metaestabilidade na Relação Homem-Técnica. In: LANCETTI, A. (Org.). Cadernos de Subjetividade: o reecantamento do concreto. São Paulo: Hucitec, 2003. P. 177-186.

GLOSSÁRIO Simondon. 2011. Disponível em: <http://www.scribd.com/doc/54040289/Glossario-Simondonem-portugues> Acesso em: 01 ago. 2011.

4 Entendemos agenciamento como "[...] todo conjunto de singularidades e traços extraídos do fluxo - selecionados, organizados, estratificados - de maneira a convergir (consistência) artificialmente e naturalmente [...]" (DELEUZE; GUATTARI, 2007, p. 88). 
HUGIN. 2011. Disponível em: <http://hugin.sourceforge.net/> Acesso em: 01 maio 2011.

LÉVY, P. As Tecnologias da Inteligência. Rio de Janeiro: Ed. 34, 1990.

MEGGS, P.B.; PURVIS, A.W. História do Design Gráfico. São Paulo: Cosac Naify, 2009.

NIKON. 2011. Disponível em: <http://www.nikon.com> Acesso em: 01 maio 2011.

PANORAMIC Network. 2011. Disponível em: <http://www.panoramic.net/www/cirkut.htm> Acesso em: 01 maio 2011.

PARENTE, A. A Arte do Observador. Revista FAMECOS, Porto Alegre, n. 11, p. 124-129, dez. 1999.

PARENTE, A. Entrevista com André Parente. Psicologia \& Sociedade, Porto Alegre, v. 16, n. 2, maio/ago. 2004. Disponível em: <http://www.scielo.br/scielo.php?script=sci_arttext\&pid=S0102-71822004000200002> Acesso em: 01 maio 2011.

PARENTE, A. Enredando o Pensamento: redes de transformação e subjetividade. In: PARENTE, A. (Org.). Tramas da Rede. Porto Alegre: Sulina, 2010.

PARENTE, A. Figuras na Paisagem. 2010. Disponível em: <http://andreparente.net/figurasnapaisagem/\#/panoramas/> Acesso em: 01 maio 2011.

PELBART, P.P. Vida Capital: ensaios de biopolítica. São Paulo: Iluminaras, 2009.

ROUNDSHOT. Thundorf: Seitz Phototechnik, 2011. Disponível em: <http://www.roundshot.ch> Acesso em: 01 maio 2011.

SIMONDON, G. A Gênese do Indivíduo. In: LANCETTI, A. (Org.). Cadernos de Subjetividade: o reecantamento do concreto. São Paulo: Hucitec, 2003. P. 97-118.

SIMONDON, G. El modo de existencia de los objetos tecnicos. Buenos Aires: Prometeo Libros, 2008.

UNIVERSAL Leonardo. London: University of Arts, 2011. Disponível em: <http://www.universalleonardo. org/> Acesso em: 26 jun. 2011.

Recebido para publicação em dezembro de 2010 Aprovado para publicação em dezembro de 2010

\section{André Noronha Furtado de Mendonça}

Bacharel em Design Gráfico, mestre em Design e Tecnologia pelo PGDesign/UFRGS e doutorando em Informática na Educaçao pelo Programa de Pós Graduação em Informática na Educação/PGIE/UFRGS. Porto Alegre-RS/Brasil.

Email: andrefurtado@terra.com.br

\section{Andresa Ribeiro Thomazoni}

Psicóloga pela Universidade Federal do Rio Grande do Sul/UFRGS, Mestre em Psicologia Social e Institucional/UFRGS e doutoranda em Informática na Educação/UFRGS. Integrante do grupo de pesquisa Corpo, Arte e Clínica nos Modos de Trabalhar e Subjetivar/UFRGS. Experiência em arte, loucura, tecnologias digitais, processos de criação e psicologia social e doutoranda em Informática na Educaçao pelo PGIE/UFRGS. Porto Alegre-RS/Brasil.

Email: andresa.thomazoni@gmail.com

\section{Tânia Gomes Bischof}

Possui graduação em Psicologia pela Universidade do Vale do Rio dos Sinos, Pós-Graduação em Psicologia Organizacional e Mestrado em Psicologia Social e da Personalidade pela Pontifícia Universidade Católica do Rio Grande do Sul. É doutoranda em Informática na Educaçao pelo PGIE/UFRGS. Porto Alegre-RS/Brasil.

Email: taniabischoff@uol.com.br

\section{Tania Mara Galli Fonseca}

Possui graduação em Psicologia pela Pontifícia Universidade Católica do Rio Grande do Sul, mestrado em Educação pela Universidade Federal do Rio Grande do Sul (1978). Doutorado em Educação pela Universidade Federal do Rio Grande do Sul e Pós-doutorado pela Universidade de Lisboa. Atualmente é Professor Titular da Universidade Federal do Rio Grande do Sul, docente e pesquisadora dos Programas de Pós-Graduação em Piscologia Social e Institucional e de Informática na Educação, dirige a Coleção Cartografias editada pelas editoras UFRGS e Sulina. Porto Alegre-RS/Brasil.

Email: tfonseca@via-rs.net 